\title{
Use of Series Title Authority Cross-References at a Large University Library
}

\section{Henry H. McCurley Jr. and Elizabeth J. Weisbrod}

\begin{abstract}
The purpose of this study is to determine whether users of the Ralph Brown Draughon Library at Auburn University employ the cross-references provided by the series title authority file in their searches. The authors present and discuss the results of a transaction log analysis. The analysis focuses attention on the usefulness of cross-references from series title authority records, because only searches that required such cross-references appear in the transaction log report. The study indicates that patrons do use the cross-references gathered by series title authority records.
\end{abstract}

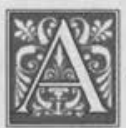

$\mathrm{s}$ the module on series and series tracings in the CONSER Cataloging Manual indicates, "when monograph or serial catalogers are asked what they consider to be the most difficult aspect of cataloging, invariably the answer is 'series.'"1 The quest for bibliographic control of monographic series may be as quixotic as the quest for the Holy Grail. It is perhaps even more futile, because in the Grail quest, it will be recalled, those armored in purity of heart had some chance of success. Unfortunately, in dealing with monographic series, purity of heart does not suffice. Those seeking to manage monographs in series must avail themselves of different arms. The best means of attaining bibliographic control over monographic series may be some form of title authority file. A well-designed series title authority file can greatly improve patron access to monographs in series by providing a consistent, established form of the title, clarifying the treatment of the series, and giving cross-references to library users.

Cross-references, a feature of many card catalogs and increasingly of online catalogs, direct the patron to the "established" form of a given heading, whether name, subject, or title. The established form of a heading is not always an obvious choice. Authors use different names, subject disciplines have many different terminologies, and publishers, editors, and authors often vary the title of a series, serial, or even an individual work over time. In a card file system, it is often possible to find what one is searching for, eventually, by approximation. This is not the case in an online system, where even a slight deviation from an established form can result in no hits and leave a searcher with no clues on how

Henry H. McCurley Jr. is a Serials Cataloger at the Ralph Brown Draughon Library, Auburn University; e-mail: hmccurle@lib.auburn.edu. Elizabeth J. Weisbrod is a Cataloger at the Ralph Brown Draughon Library, Auburn University; e-mail: eweisbro@lib.auburn.lib. The authors would like to thank Kathy Ford and Peggy Seaquist for technical assistance. 
to proceed. This article examines use of cross-references for series title searching.

This study is based on the transaction logs of the Auburn University Libraries, a member of ARL, with holdings of more than two million physical volumes, two million items in microformat, and oneand-a-half million government publications, serving a student population of more than 3,000 graduate students and 18,000 undergraduates. The main library is the Ralph Brown Draughon (RBD) Library, with branches at the College of Veterinary Medicine and the School of Architecture. Its holdings support more than 300 degree programs, including ninetysix doctoral programs, particularly in the sciences and technology. The library uses OCLC as its primary bibliographic utility and has been a NOTIS library since 1984.

In addition to the cataloging, acquisitions, circulation, and other modules, NOTIS contains a relatively sophisticated authority module. Since implementing NOTIS, the RBD has invested a great deal of time and effort in making its authority file an important aid to patron access. Until recently, attention was directed primarily to name authority, both personal and corporate, and subject authority. ${ }^{2}$ In recent years, however, greater attention has been paid to title authority, for both uniform titles and, in particular, series titles. $^{3}$

A project to establish a series authority file online began in January 1992, and by the end of 1994, the file contained more than 26,000 records. The benefits of this authority file to cataloging personnel were clear: a file of unambiguous series decisions immediately accessible to everyone in technical services, authority records that could not be misfiled (a serious problem with the existing card file), virtual elimination of duplicate records, a system of cross-references between various forms of the series title, and series titles uniformly established in AACR2 form.
Although the technical services division derived many benefits from the project, the most visible advantage to public users lay in the system of crossreferences. The series authority records provide references from invalid title variants to the established form of the series title, or to earlier and later forms of the title. There was some question, though, as to whether these cross-references were ever utilized. They do not display with keyword searching, only through title or author searching. Most staff, however, indicated that they generally used keyword rather than title to search for series, and encouraged patrons to do likewise.

Although reports on OPAC searching activity are generated monthly by the library's Automation Department, these reports normally do not describe crossreference usage. This paper employs the results of a special transaction log report to examine use of the cross-reference feature of series authority records by cata$\log$ users.

\section{Description of Authority File}

As of May 1994, the RBD had 24,224 series authority records online and slightly more than half of these records $(12,385$, or $51.13 \%$ ) contained cross-references. This number includes authority records for traced and untraced series, and multipart items established under title. All of the cross-references appear to technical services users of NOTIS, but cross-references only show on the OPAC for series and multipart items that are traced.

Cross-references from invalid title variants are created by the 410 and 430 fields on the authority records, and cross-references from earlier and later forms of the series titles are created by the 510 and 530 fields. A search for any of these forms will cause a message to appear on the OPAC with instructions to search under the valid form of the title or to search also under another form (or forms) of the title (see figure 1). 


\begin{tabular}{l} 
FIGURE 1 \\
Example of Series Authority Record \\
\hline NOTIS CATALOGING NBF1975 \\
LTAU DONE \\
AU- NBF1975 FMT A RT z DT 04/14/92 R/DT 05/02/95 STAT mm E/L n \\
SRC LANG ROM \& MOD UNIQUE n GOVT ф S/SYS n D/I n SUBD NUM a S/TYP z \\
NAME c SUBJ a SER c KIND a H/ESTAB a T/EVAL a IP a RULES c \\
010: : la n 42019881 \\
040: : la DLC Ic DLC Id DLC \\
130: 0: la Progress in water technology. \\
410/1:20: la International Association on Water Pollution Research. It Progress in water \\
technology \\
530/1: 0: Iw b la Water science and technology \\
642/1: : la v. 12, nr. 2 I5 DLC \\
643/1: : la Oxford la New York lb Pergamon Press \\
644/1: : la f I5 DLC \\
645/1: : la t I5 DLC \\
646/1: : la s I5 DLC \\
670/1: : la Seminar on Eutrophication of Deep Lakes. Eutrophication of deep lakes, 1980. \\
670/2: : la Other Series (Serial); numbered \\
670/3: : la ADD \& TRACE; CLASS SEPARATELY \\
670/4: : la Marc for wk cat aau3018
\end{tabular}

The NOTIS OPAC has a feature that "redirects" a user's search from an earlier to a later form or a later to an earlier form, or from an invalid title variant to the established form. When a user receives a "search also" or "search also under" message, he or she may select the number of the cross-reference from the screen, which will then redirect the search and retrieve titles under the established form of the title. If, for example, a patron searches under the heading "Marriage and Family Review" (which is an invalid variant because the established form

\section{FIGURE 2}

Example of Cross-Reference for Series Title

Search Request: T=MARRIAGE AND FAMILY REVIEW AU Books, Journals, Docs Search Results: 1 Entry Found Title Index

\section{MARRIAGE AND FAMILY REVIEW}

1 *Search Under: MARRIAGE FAMILY REVIEW

STArt over Type number to display record

HELp

OTHer options

NEXT COMMAND: 
contains an ampersand), the result will be the message shown in figure 2. Rather than retyping the search, the patron has only to select the cross-reference by typing " 1 " in order to be redirected immediately to the titles that fall under the es-

Clearly, the cross-references provided by the series authority records are potentially very useful to those who are searching for titles in monographic series but are having difficulty because of variants.

tablished form of the series heading, as shown in figure 3.

Clearly, the cross-references provided by the series authority records are potentially very useful to those who are searching for titles in monographic series but are having difficulty because of variants. However, the extent to which they were actually being used was not at all clear.

\section{Literature Review}

Although no studies concerning title or series title cross-reference use were found, the literature contains a number of studies examining the value of subject and name cross-references. Noelle Van Pulis and Lorene Ludy examined subject searching at the Ohio State University Libraries in $1988 .{ }^{4}$ The libraries' online system, LCS, contained the machinereadable form of the Library of Congress Subject Headings ( $L C S H$ ) which provided "see" and "see also" references, classification numbers, and scope notes for subject headings used in the catalog. At this time, LCS did not have keyword searching capabilities. The study found that subject search terms matched $L C S H$ vocabulary about 80 percent of the time and that 14 percent of these terms matched see references. Overall, cross-references directed users to appropriate terminology in 6 percent of all subject searches. Other studies found cross-references less

FIGURE 3

Results of Series Title Redirect

Search Request: T=MARRIAGE FAMILY REVIEW

Search Results: 34 Entries Found

AU Books, Journals, Docs

Title Index

MARRIAGE FAMILY REVIEW

1 AIDS AND FAMILIES $<$ V 13 NOS $1>$ (AU)

2 ALTERNATIVE HEALTH MAINTENANCE AND HEALING S $<$ V 11 NO $3>$ (AU)

3 ALTERNATIVES TO TRADITIONAL FAMILY LIVING $<$ V 5 NO $2>$ (AU)

4 AMERICAN FAMILIES AND THE FUTURE ANALYSES OF $<\mathrm{V} 18$ NOS $3>$ (AU)

5 CHARYBDIS COMPLEX REDEMPTION OF REJECTED MAR $<\mathrm{V} 10 \mathrm{NO} 1>$ (AU)

6 CHILDHOOD DISABILITY AND FAMILY SYSTEMS $<\mathrm{V} 11 \mathrm{NO} 1>$ (AU)

7 CORPORATIONS BUSINESSES AND FAMILIES $<$ V 15 NOS $3>$ (AU)

8 CROSS CULTURAL PERSPECTIVES ON FAMILIES WORK $<$ V 14 NO $1>$ (AU)

9 CULTS AND THE FAMILY $<\mathrm{V} 4$ NO $34>$ (AU)

10 DEVIANCE AND THE FAMILY $<$ V 12 NO $1>$ (AU)

11 EXEMPLARY SOCIAL INTERVENTION PROGRAMS FOR M $<$ V 21 NO $1>$ (AU)

CONTINUED on next page

STArt over Type number to display record $\quad<$ F8 $>$ FORward page

HELP

OTHer options

NEXT COMMAND: 
effective than keyword searching or other system features in resolving problem searches. In 1984, Arlene G. Taylor investigated what effect a name authority file would have had on "nohit" author searches on a NOTIS system at Northwestern University. ${ }^{5}$ At that time, Northwestern did not have an online authority file. Using actual searches from transaction logs, she matched users' input against the LC authority file and, for those names that LC had not established, against authority records established according to LC practice. She found that only 6.4 percent of no-hit author searches would have resulted in a successful search if the cross-references had been present. She suggested that several system modifications would have been more helpful than cross-references. In 1992, Joan Cherry studied "zero-hit" subject searches at the University of Toronto Libraries. ${ }^{6}$ The libraries' OPAC did not contain subject cross-references, although title, keyword title, and keyword subject searching were available to users. She found "that keyword subject, keyword title, or title searches using the original query from the user's zero-hit subject search were as fruitful or more fruitful than new searches constructed from cross-references provided by $\mathrm{LCSH} .{ }^{\text {"7 }} \mathrm{Al}$ though these other types of search strategies would have produced successful results, they were seldom used. She suggested that educating users about $\mathrm{LCSH}$ or providing cross-references on the OPAC would not help produce successful outcomes for most zero-hit subject or name searches. Conversely, Alexis Jamieson, Elizabeth Dolan, and Luc Declerck found that more than 50 percent of name see references and nearly 70 percent of see references for subjects on LC authority records could not be matched with catalog records using keyword searching. ${ }^{8}$ They concluded that keyword searching was not an adequate substitute for a crossreference structure. Perhaps cross-refer- ences, although less sophisticated than other approaches, provide an essential link for some searchers.

\section{Limitations of the Study}

This study provides a count of instances in which a user actively followed a crossreference through the redirect system. The authors cannot know for certain, though, precisely how much the cross-references are used or whether they are used in search of series. For example, a searcher may have used a cross-reference but bypassed the redirect system by retyping the search using the established heading rather than selecting the number of the cross-reference. This sort of usage would not have been included in the study. Conversely, some redirects may have been counted that were not the result of series title searching. For instance, a user may have encountered a cross-reference for a series while browsing a corporate author display or searching for a book with a similar title. The user may not have been searching for that particular series, but selected the cross-reference out of curiosity (or confusion). Transaction logs do not reveal why a user chose a particular crossreference or for what materials the user was actually searching.

\section{Methodology}

The library's transaction logs record all instances of redirects from cross-references. Using these logs, the library's Automation Department produced a report that located and printed out all instances in which a user selected a title cross-reference for the period January 1, 1992, through May 31, 1994. As previously mentioned, January 1992 marks the beginning of the project to load the series authority file. Some of the cross-references selected were for uniform titles (Gawain and the Green Knight being a particular favorite). Once these were eliminated, the remainder consisted of 2,793 redirects of series titles or multipart items entered under title. In other words, 


\begin{tabular}{|c|c|c|c|c|c|c|}
\hline \multirow[b]{3}{*}{ Month } & \multicolumn{4}{|c|}{$\begin{array}{c}\text { TABLE } 1 \\
\text { Series Title Redirects }\end{array}$} & & \\
\hline & \multicolumn{2}{|c|}{1992} & \multicolumn{2}{|c|}{1993} & \multicolumn{2}{|c|}{1994} \\
\hline & $\begin{array}{c}\text { Redirects } \\
\text { Used }\end{array}$ & $\begin{array}{l}\text { Authority } \\
\text { Records } \\
\text { Loaded* }\end{array}$ & $\begin{array}{c}\text { Redirects } \\
\text { Used }\end{array}$ & $\begin{array}{l}\text { Authority } \\
\text { Records } \\
\text { Loaded }\end{array}$ & $\begin{array}{l}\text { Redirects } \\
\text { Used }\end{array}$ & $\begin{array}{c}\text { Authority } \\
\text { Records } \\
\text { Loaded }\end{array}$ \\
\hline January & 0 & 227 & 134 & 8,082 & 131 & 11,890 \\
\hline February & 7 & 1,188 & 139 & 8,990 & 125 & 11,978 \\
\hline March & 24 & 1,726 & 139 & 10,343 & 120 & 12,199 \\
\hline April & 40 & 2,251 & 144 & 10,871 & 101 & 12,287 \\
\hline May & 67 & 2,837 & 177 & 11,126 & 119 & 12,385 \\
\hline June & 37 & 3,681 & 121 & 11,234 & & \\
\hline July & 77 & 4,172 & 129 & 11,344 & & \\
\hline August & 72 & 4,875 & 125 & 11,449 & & \\
\hline September & 57 & 5,315 & 98 & 11,511 & & \\
\hline October & 87 & 6,008 & 158 & 11,591 & & \\
\hline November & 121 & 6,670 & 136 & 11,668 & & \\
\hline December & 51 & 7,720 & 57 & 11,810 & & \\
\hline
\end{tabular}

the report recorded each instance in which a user, after receiving a search under or search also under display, entered the line number of the established form of a title and was redirected to the titles that fall under the established form, or to an earlier or later title of the series heading. The report recorded only searches on the public catalog, not those made on the technical services portion of NOTIS.

It should be emphasized that these 2,793 searches do not represent the total number of series title searches that occurred during the period under examination. Rather, they represent only those series title searches that satisfied the very specific conditions necessary to produce a cross-reference from a series title authority record: (1) a series authority record for the title must have been online at the time of the search, and (2) the search entered must have been for either an invalid form of the title that appeared on the authority record for that title (eliminating, for example, typographical errors) or an earlier or later form of the title.

\section{Results}

The report provides a picture of the types and numbers of title cross-references employed by users of Auburn University's online catalog. Two areas were examined: the distribution of redirects over the twenty-nine-month period under examination and the frequency of their use, and the subject areas in which series titles were redirected through cross-references. ${ }^{9}$

\section{Distribution}

The report located 2,793 redirects distributed over a twenty-nine-month period. As table 1 shows, the number of redirects per month increased steadily as the project to load the series authority file progressed. The numbers also rise and fall in accordance with Auburn's academic quarters (see table 1).

Although the numbers of redirects steadily increased through 1993, the usage appears to have dropped somewhat in the first five months of 1994. Although many explanations are possible, one reason may be that the number of keyword 
searches began to increase as the number of title searches decreased proportionally. As stated earlier, the cross-references are not available through keyword searching, only title or author searching.

\section{Frequency of Use}

The report also indicated the number of times each title was redirected through a cross-reference. As table 2 shows, the number of searches per title ranged from one, in the majority of cases, to 115 (see table 2).

As shown, a large number of titles were redirected through a cross-reference only once. On the one hand, a small number of titles accounted for a large number of the redirects recorded in the study. Forty-one of the titles $(4.45 \%)$ were redirected a total of 944 times, or 33.8 percent of the total. On the other hand, 470 titles (51.03\%) were redirected only once during the 29-month period. Some of the disparity in cross-reference usage may be the result of series use. Heavily used series titles were probably redirected more frequently than lightly used ones. In the case of some of the titles that show up fre-

quently in this study, the authors know, from discussion with reference personnel, that they are heavily used.

However, series use alone may not completely account for the large number of redirects that some titles produced. For

\section{Some of the disparity in cross- reference usage may be the result of series use.}

instance, some series are routinely cited by only their series title and volume number, whereas others are commonly cited by the individual volume title. Those cited by series title would have more opportunities to bring a cross-reference into play than those that are not. Other situations, such as a series title similar to that of a monograph or a series title also used as a subject heading, also may have contributed to some titles' use.

Another factor may be the series title itself. The titles that accounted for most of the cross-reference usage were searched frequently, but the search matched a crossreference rather than the form of title selected by the cataloger.

TABLE 2 Frequency Distribution of Redirects

\begin{tabular}{|cr|rc}
$\begin{array}{c}\text { Number of Re- } \\
\text { directs per Title }\end{array}$ & $\begin{array}{c}\text { Number of } \\
\text { Titles }\end{array}$ & $\begin{array}{r}\text { Number of Re- } \\
\text { directs per Title }\end{array}$ & $\begin{array}{c}\text { Number of } \\
\text { Titles }\end{array}$ \\
\hline 1 & 470 & 16 & 1 \\
2 & 180 & 20 & 2 \\
3 & 93 & 22 & 1 \\
4 & 58 & 23 & 1 \\
5 & 23 & 24 & 3 \\
6 & 25 & 26 & 1 \\
7 & 13 & 29 & 1 \\
8 & 10 & 30 & 1 \\
9 & 8 & 35 & 2 \\
10 & 8 & 39 & 1 \\
11 & 6 & 45 & 1 \\
12 & 3 & 48 & 1 \\
13 & 3 & 49 & 1 \\
14 & 1 & 70 & 1 \\
15 & 1 & 115 & 1 \\
\hline
\end{tabular}
The series titles in question, then, must present some special difficulties for library patrons. This points to a difficulty with a number of series titles: the title is constructed by the cataloger and is not an intuitive choice for searchers. Series titles consisting of initialisms, series indexed under a subseries title, or series titles that appear in several different forms may lead users to search under a crossreference.

Quirks of the online system account for a number of the redirects. 
Although the reason for following a cross-reference is not always apparent, in the case of the most frequently appearing title, Marriage \& Family Review, the reason for the difficulty is clear. The title contains an ampersand, which is not searchable on NOTIS. In the absence of a cross-reference from the series authority record, the patron would have had to know to search "Marriage Family Review." Certainly this is an instance in which the authority record provided a useful cross-reference.

\section{Subject Areas}

This study included 921 different series and multipart item titles. For purposes of analysis, the authors divided the redirects into three general subject areas: humanities (Library of Congress classes A, B [except BF], M, N, P, and Z), social sciences (classes BF, C, D, E, F, G, H, J, K, and L), and science and technology (classes $\mathrm{Q}, \mathrm{R}$, $\mathrm{S}$, and T). ${ }^{10} \mathrm{~A}$ few additional titles were for government publications with SuDocs call numbers, while other titles covered such a range of classifications that they could not be characterized as subject specific. As table 3 shows, the largest number of titles were in science and technology.

In terms of the number of redirects, series in the areas of science and technology also predominated. As table 4 shows, over half the searches resulting in redirects were for series titles in science and technology.

\begin{tabular}{|lcc|}
\hline \multicolumn{3}{|c|}{$\begin{array}{c}\text { TABLE 3 } \\
\text { Number of Series Titles } \\
\text { Appearing in Study }\end{array}$} \\
\hline \hline Subject Area & Count & Percent \\
\hline Humanities & 191 & $20.74 \%$ \\
Social sciences & 217 & 23.56 \\
Science \& tech. & 436 & 47.34 \\
Gov't. docs. & 17 & 1.85 \\
No specific subject & 60 & 6.51 \\
Total & 921 & 100.00 \\
\hline
\end{tabular}

\begin{tabular}{|lcc|}
\hline \multicolumn{3}{|c|}{ TABLE 4 } \\
Redirects by Subject Area \\
\hline \hline & $\begin{array}{l}\text { No. cross- } \\
\text { refs used }\end{array}$ & Percent \\
\hline Subject Area & 430 & $15.40 \%$ \\
\hline Humanities & 588 & 21.05 \\
Social sciences & 1499 & 53.67 \\
Science \& tech. & 129 & 4.62 \\
Gov't. docs. & 147 & 5.26 \\
No specific subject & 2,793 & 100.00 \\
Total & \\
\hline
\end{tabular}

As shown in table 5, eleven series titles were redirected more than twenty-five times during the period of study. Once again, science and technology series were the most numerous with eight titles, while two titles were government documents and one was from the social sciences. Interestingly, there are two instances in which both the earlier and later forms of a series title appear in the list. Research Monograph (National Institute on Drug Abuse) and NIDA Research Monograph are related titles, as are Water Science and Technology and Progress in Water Technology. For purposes of this study, the authors counted titles separately rather than as one series.

Several factors may account for the heavy cross-reference usage in the science and technology series. Series titles in the sciences may be more complex than in other subject areas, involving complicated relationships between main and subseries. Perhaps publishing practices in the sciences produce more series titles than other areas, and thus provide more opportunities for cross-reference use. Another reason may lie in how the scientific literature is cited. If works in a series are commonly cited by series title and volume number rather than by individual title, more cross-references to the series title may be used. Other factors such as teaching practices in the sciences and the overall structure of the literature also may play a role. Locally, several factors at Auburn University may contribute to the predominance of science and technology 


\begin{tabular}{|lll|}
\hline \multicolumn{3}{|c|}{ TABLE 5 } \\
No. of & \multicolumn{1}{|c|}{ Series Titles Redirected More Than 25 Times } \\
Redirects & \multicolumn{1}{c}{ Series Title } \\
\hline 26 & Ellis Horwood Series in Biochemical Pharmacology & Subject \\
29 & Research Monograph (National Institute on Drug Abuse) & Socument \\
30 & Family Therapy Collections & Sci. \& tech. \\
35 & Proceedings of SPIE-The International Society & Sci. \& tech. \\
& for Optical Engineering & \\
35 & ASTM Special Technical Publication & Sci. \& tech. \\
39 & Monograph Series (American Chemical Society) & Sci. \& tech. \\
45 & Transportation Research Record & Sci. \& tech. \\
48 & Water Science and Technology & Sci. \& tech. \\
49 & Progress in Water Technology & Sci. \& tech. \\
70 & NIDA Research Monograph & Document \\
115 & Marriage \& Family Review & Social sciences \\
\hline
\end{tabular}

titles. Over half of Auburn's students (51\%) are enrolled in degree programs in the sciences and technology, as compared to 38 percent in the social sciences and only 11 percent in the humanities. Because of the enrollment, series in the sciences and technology may see more use than those in other subject areas. Finally, the makeup of the local catalog may play a role. Although the number of series authority records in each subject area is not known, perhaps the online catalog simply contains more authority records for science and technology series than for other subject areas.

\section{Conclusion}

The report indicated that cross-references for series titles are used. The number of redirects rose as the number of cross-references in the database increased, indicating that patrons and staff not only encountered the cross-references, but actively followed them. Most titles appearing in this study were redirected by a cross-reference only once during the period of this study. However, several titles were redirected a large number of times, perhaps because of heavy use of the series, frequent citation by series title in the literature, or a difficult or complex established form of the title.

Overall, cross-references for series in the sciences and technology were more heavily used than those for other subject areas. Science and technology series accounted for nearly half the titles in the study and were redirected through crossreferences many more times than titles in other subject areas. Although Auburn University has an emphasis in this area, other factors, such as the complexity of series titles, the structure of the literature, publishing practices, or even teaching methods in the sciences, also may have contributed to the predominance of science and technology.

Further investigation may provide a more complete picture of cross-reference usage. Studies into how much series title searching occurs, what sorts of series searches users employ, and the types of series titles that benefit from cross-references may help determine how library catalogs can better serve users.

\section{Notes}

1. Jean L. Hirons, CONSER Cataloging Manual, Module 12 (Washington, D.C.: Library of Congress, Cataloging Distribution Service, 1993), 3. 
2. Helen Goldman and David M. Smith, "Name Authority in a NOTIS Environment-Auburn University Libraries," Cataloging \& Classification Quarterly 9 (1989): 121-31.

3. Henry H. McCurley Jr., "Implementation of an Online Series Authority File at Auburn University," Cataloging \& Classification Quarterly 18 (1993): 41-58; also, Henry H. McCurley Jr., "The Benefits of Online Series Authority Control," Technical Services Quarterly 11 (1994): 33-50.

4. Noelle Van Pulis and Lorene E. Ludy, "Subject Searching in an Online Catalog with Authority Control," College \& Research Libraries 49 (Nov. 1988): 523-33.

5. Arlene G. Taylor, "Authority Files in Online Catalogs: An Investigation of Their Value," Cataloging \& Classification Quarterly 4 (spring 1984): 1-17.

6. Joan M. Cherry, "Improving Subject Access in OPACs: An Exploratory Study of Conversion of Users' Queries," Journal of Academic Librarianship 18 (May 1992): 95-99.

7. Ibid., 99.

8. Alexis J. Jamieson, Elizabeth Dolan, and Luc Declerck, "Keyword Searching vs. Authority Control in an Online Catalog," Journal of Academic Librarianship 12 (Nov. 1986): 277-83.

9. The authors had hoped to provide some comparison between the number of patron searches and the number of staff searches, but identifying the type of searcher was not possible. Of the searches, 32.76 percent are known to have been made from library staff terminals located at reference desks, work areas, and in technical services, while more than half of the searches $(50.81 \%)$ were made from public terminals or by dialing into the library. (The remaining 16.43 percent of the searches were recorded as network searches, which could have been made by public or staff users.) Although the percentage of searches originating from the public terminals suggests that patrons are using the cross-references, some of the searches could have been made by library personnel assisting users.

10. Auburn University's main library (the Ralph Brown Draughon Library) organizes its collection using these broad subject categories. The second floor holds humanities materials; the third floor, social sciences materials; and the fourth floor, science and technology materials.

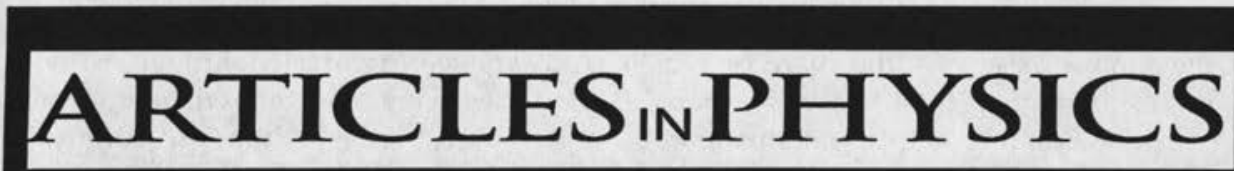

A NEW DOCUMENT DELIVERY SERVICE FROM THE AMERICAN INSTITUTE OF PHYSICS AND EBSCOdOC

ARTICLES IN PHYSICS gives you immediate access to more than 30,000 scientific and technical publications from AIP, its Member Societies, and other leading scientific publishers worldwide.

Articles In Physics is also an excellent source for material in disciplines other than the physical sciences. Backed by EBSCOdoc's extensive collection and its worldwide resources, researchers and librarians around the world can obtain articles rapidly via mail, fax, or Internet fax. Turnaround time for in-house titles is $\mathbf{2 4}$ hours.

\section{A L L T O L L - F RE E $800-480$ - P H Y S}

international +01-415-259-6002 fax +01-415-259-6044

e-mail articles@aip.org URL: http://www.aip.org/articles.html

OR WRITE TO: Articles In Physics • 1722 Gilbreth Road • Burlingame, CA 94010

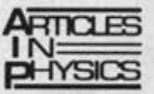

